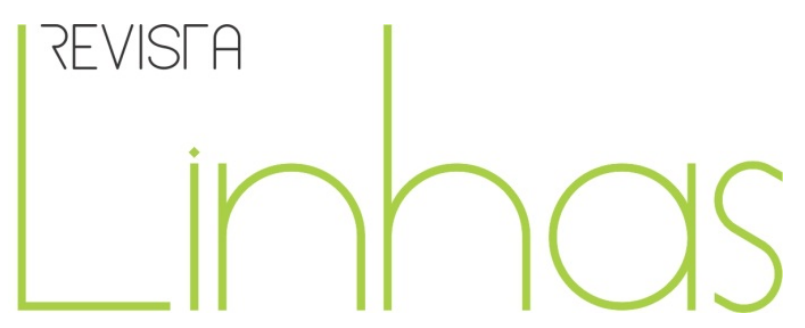

\title{
História da educação, instituições escolares, fontes e pesquisa em arquivos na região oeste do Paraná
}

\section{Resumo}

Este texto discute a pesquisa em arquivos na região Oeste do Paraná e a questão das fontes históricas para a investigação sobre as instituições escolares. Nas últimas décadas, houve uma ampliação da discussão sobre a conservação das fontes para o conhecimento do patrimônio cultural e histórico, todavia, os pesquisadores ainda encontram dificuldades, especialmente aquelas relacionadas ao acesso e à conservação dos documentos. No caso do oeste paranaense, embora se trate de uma região de colonização recente, década de 1940, quando comparada ao restante do Estado do Paraná, a situação das fontes é precária e descuidada. Existem poucos arquivos que acondicionam documentos que preservam a memória coletiva. Os acervos das instituições escolares exercem importante papel no processo de levantamento, catalogação e acondicionamento de documentos que se constituem como fontes para pesquisa sobre a história da educação da região. Para a pesquisa sobre instituições escolares são necessários o conhecimento dos arquivos públicos e privados da região. Elencamos os principais arquivos da região que podem servir para a reconstituição da escolarização e da história da educação da região.

Palavras-chave: Educação; História da educação; Instituições escolares; Oeste paranaense.
Cézar de Alencar Arnaut de Toledo

Doutor em Educação pela Universidade

Estadual de Campinas - Unicamp caatoledo@uem.br

Rodrigo Pinto de Andrade

Doutorando em Educação pela

Universidade Estadual de Maringá - UEM

pr_rodrigoandrade@yahoo.com.br

\section{Para citar este artigo:}

TOLEDO, Cézar de Alencar Arnaut de; ANDRADE, Rodrigo Pinto de. História da educação, instituições escolares, fontes e pesquisa em arquivos na região oeste do Paraná. Revista Linhas. Florianópolis, v. 15, n. 28, p. 175-199, jan./jun. 2014. 


\title{
History of education, educational institutions, sources and research into archives in the west region of Paraná
}

\begin{abstract}
This paper discusses the research into archives in the west of Paraná and the question of the historical sources for studying about educational institutions. In the last decades, there were an increasing in discussion about the conservation of sources for understanding the historical and cultural heritage, however, the researchers have still difficulties, especially those related to access to and conservation of documents. In the case of west of Paraná, although it is a region of recent colonization, 1940, it being compared to the rest of the state of Paraná, the sources situation is precarious and careless. There are few files which wrap the documents which preserve the collective memory. The collections of educational institutions play an important role in process of survey, catalogue and wrap documents which constitute sources for research on the history of education process in the region. For research on educational institutions the knowledge of public archives as much as in the private ones in the region are needed. We list the core files of the region which can serve to replenish the education and the history of education in the region.
\end{abstract}

Keywords: Education; History of education; School institutions; West of Paraná. 


\section{Introdução}

Este texto tem por objetivo apresentar uma reflexão sobre o levantamento, a catalogação e a análise das fontes para a pesquisa sobre instituições escolares na região oeste do Paraná e reforçar a necessidade de organização e registro de arquivos que possibilitem a preservação das fontes para a pesquisa sobre instituições escolares nessa região de colonização recente.

No Brasil, a preocupação em relação aos arquivos para pesquisa educacional é recente e pouco disseminada; no entanto, a pesquisa em história da educação é realizada mediante a análise de documentos conhecidos ou reconhecidos como fontes para a investigação histórica. Os arquivos são elementos importantes no processo de pesquisa, pois eles disponibilizam as fontes que servem de base para realização da investigação histórica.

A história da educação tem passado por uma discussão e renovação do conceito de fontes, escritas, iconográficas, pictóricas, audiovisuais ou arquitetônicas, importantes para investigar o passado. A ampliação do conceito do que se pode utilizar como fonte passou a contemplar a possibilidade do estudo de instituições escolares como elementos importantes na escrita da história da educação regional e brasileira.

Para discutir a temática proposta, inicialmente serão analisadas a trajetória da pesquisa em história da educação no Brasil e a pesquisa sobre instituições escolares. Em seguida, será discutida a questão das fontes para pesquisas sobre instituições escolares: levantamento, organização, catalogação e análise dos documentos. Por fim, será analisada a pesquisa em arquivos, com ênfase na importância dos arquivos escolares. Também serão apresentados os principais arquivos que acondicionam e organizam as fontes para a pesquisa sobre instituições escolares no oeste paranaense. 


\section{Pesquisa em História da Educação no Brasil}

A história da educação, enquanto disciplina, tem sua trajetória diretamente associada ao curso de Pedagogia, que começou a se desenvolver em alguns países da Europa e nos Estados Unidos. A disciplina apareceu nas universidades europeias no final do século XIX para atender à necessidade de um ensino sistemático da pedagogia. No Brasil, desenvolveu-se, sobretudo, nas escolas do chamado Normal e nos cursos de formação de professores (LOPES; GALVÃO, 2001). A história da educação é uma disciplina bastante recente. Segundo Clarice Nunes e Marta Maria Chagas de Carvalho, "a história da educação, como disciplina escolar, é apresentada pelo seu conteúdo e pela organização institucional que lhe deu suporte no seu momento fundador: o século XIX" (NUNES; CARVALHO, 2005, p. 19).

O curso de pedagogia foi instituído pelo Decreto-Lei n.1.190, de 4 de abril de 1939; a disciplina de história da educação tornou-se obrigatória no terceiro ano do curso. Com a Lei Orgânica de Ensino Normal, instituída pelo Decreto-Lei n. 8.530, de 2 de janeiro de 1946, ela passou a fazer parte do currículo de todas as escolas do Normal do País, com o nome de "história e filosofia da educação". A história da educação se constituiu como disciplina obrigatória não apenas das escolas do Normal, mas também do curso de pedagogia (SAVIANI, 2013b).

Embora o objeto da história da educação sejam as sociedades e suas produções materiais, ela, enquanto disciplina não se desenvolveu como uma área da história. Lopes e Galvão destacam ter sido praticamente ignorada pelos historiadores de ofício (LOPES; GALVÃO, 2001). Saviani afirma que se desenvolveu "como um domínio de caráter pedagógico paralelamente, e, mesmo, à margem das investigações propriamente historiográficas" (SAVIANI, 2013b, p. 167).

Devido à influência da Escola Nova, que pôs a psicologia, a biologia e a sociologia como disciplinas centrais para educação e para compreensão do fenômeno educativo, a história da educação foi considerada secundária no próprio campo da educação (LOPES; GALVÃO, 2001). O fato de a trajetória da disciplina estar ligada à pedagogia dificultou sua 
constituição como uma área de pesquisa propriamente dita. António Nóvoa tem uma visão semelhante e diz que a história da educação tem sido considerada uma disciplina menor, tanto por uns como por outros: uns a consideram como um prolongamento da História; outros não lhe concedem o espaço de intervenção pedagógica que lhe pertence (NÓVOA, 2004). Todavia, na percepção de Saviani, o estágio atual da história da educação ocupa lugar próprio no espaço acadêmico da pedagogia, no qual se firmou como disciplina obrigatória (SAVIANI, 2013a).

De acordo com Mirian Jorge Warde, as pesquisas em história da educação no Brasil só tiveram início na década 1950. Surgiu no Setor de Educação da Universidade de São Paulo, com um projeto de construção de uma história da educação brasileira, com base num levantamento de documentos originais (WARDE, 2006). Nesse período, não havia muitas pesquisas nessa área, fato evidenciado pela inexistência de programas de pós-graduação em educação. Somente nas décadas de 1970-1980, durante o Regime Militar, surgiram e se expandiram os programas de pós-graduação em educação em várias regiões do País. Saviani afirma que "foi com a institucionalização dos programas de pós-graduação, a partir da década de 1970, que as pesquisas em educação, de modo geral, e, especialmente, na área de história da educação, ganharam impulso" (SAVIANI, 2013b, p, 167).

As pesquisas, nesse período, na percepção de Paolo Nosella e Ester Buffa, possuíam duas características principais, a saber: a escolarização da produção da pesquisa e a reação à política dos governos militares (NOSELLA; BUFFA, 2005). Os temas mais comuns eram aqueles que discutiam a relação entre educação e sociedade.

Houve, nesse período, um fortalecimento do pensamento crítico e um retorno aos autores clássicos. Os estudos sobre a sociedade eram os mais frequentes. Num outro momento da historiografia da educação brasileira, a instituição escolar passou a receber mais atenção. Esta terceira fase teve início nos anos 1990 e pode ser caracterizada pela consolidação da pós-graduação no Brasil (NOSELLA; BUFFA, 2009).

Intensamente influenciada pela nova história e pela história cultural, a produção historiográfica desse período privilegiou questões mais pontuais da historiografia 
educacional, com objetos singulares, descolados de seu quadro maior. Sob a alegação de que o estudo da sociedade em sua totalidade era insuficiente para explicar as particularidades histórico-educacionais, ganhou impulso significativo a investigação de fenômenos educativos isolados como possibilidade de respostas às indagações que se faziam. Esse período deixou como legado positivo a diversificação teórico-metodológica e a ampliação das linhas de investigação, o que abriu caminho para pesquisas de objetos aparentemente pontuais, os quais, quando analisados em seu quadro maior, podem fornecer subsídios relevantes para a construção da história da educação sob outros prismas, que privilegiam as peculiaridades da história regional, sempre articulada com a história geral (NOSELLA; BUFFA, 2006).

A história da educação é um campo subordinante na classificação históricoeducativa, pois nele estão inseridos a história da escola, o estudo das ideias pedagógicas, a história da pedagogia, da cultura escolar, da legislação educacional, das instituições escolares e de tudo que se ocupe historicamente da educação (RAGAZZINI, 1999).

\section{Pesquisa sobre instituições escolares}

A pesquisa sobre instituições escolares conquistou amplo espaço nos programas de pós-graduação em educação. Desde a década de 1990, a temática que discute a história e a historiografia das instituições educativas atraiu um considerável número de pesquisadores, vinculados, em sua maioria, à história da educação (ARNAUT DE TOLEDO; ANDRADE, 2013). A possibilidade de se escrever a história da educação brasileira e regional sob um prisma diferente daquele que dá espaço apenas às narrativas emanadas de documentos oficiais tem sido um importante elemento motivador para as pesquisas sobre instituições escolares. É uma proposta que visa à valorização das peculiaridades regionais, sem desconsiderar as dimensões nacionais. Ao analisar as características de

uma determinada instituição, espacial e geograficamente determinada, nasce a possibilidade de conhecer o contexto histórico-político e social que a criou (ANDRADE, 2011). 
O número de novos objetos analisados a partir de sua historicidade tem crescido consideravelmente. Novos temas, como: instituições escolares, práticas educativas, políticas educacionais, educação rural, educação indígena, educação especial, educação a distância, entre outros, entraram na pauta da historiografia da educação. Sobre a importância dos estudos das instituições escolares para a história da educação brasileira, Dermeval Saviani salienta que "propor-se a reconstruir historicamente as instituições escolares brasileiras implica a existência dessas instituições que, pelo seu caráter durável, têm uma história que nós não apenas queremos, mas também necessitamos conhecer" (SAVIANI, 2013a, p.29).

A instituição é produto da ação humana. Ela é voltada a atender a necessidades presentes. No caso das instituições escolares, especificamente, é correto dizer que elas surgem para atender a necessidades humanas, pois não é toda e qualquer necessidade que requer uma instituição. Segundo Saviani, a palavra instituição guarda a ideia comum de algo que não estava dado e que é criado, posto, organizado, constituído pelo homem. A instituição se apresenta como uma estrutura material e é constituída para atender às necessidades humanas. Pode-se dizer que uma instituição é criada para permanecer. As necessidades passageiras, de caráter conjuntural, são normalmente atendidas sem necessidade de se recorrer a atividades institucionalizadas (SAVIANI, 2013b).

Cabe destacar que as instituições não são entidades isoladas da realidade social, mas produto de determinações exteriores. As instituições escolares se constituem a partir da história dos homens em meio ao processo de produção da vida social. José Luís Sanfelice afirma que "as instituições não são recortes autônomos de uma realidade social, política, cultural, econômica e educacional” (SANFELICE, 2007, p. 78-79). O mesmo, em termos semelhantes, afirma Araujo (2007).

Cabe ao pesquisador que se propõe a analisar uma instituição educativa comprometer-se a discutir não apenas o funcionamento e as práticas pedagógicas daquela escola, mas averiguar as múltiplas dimensões que cercaram sua implantação, consolidação e desenvolvimento, ou seja, a escola não deve ser estudada como fim em si mesma. Justino Magalhães afirma: 
Compreender e explicar a existência histórica de uma instituição educativa é, sem deixar de integrá-la na realidade mais ampla que é o sistema educativo, contextualizá-la, implicando-a no quadro da evolução de uma comunidade e de uma região, é por fim sistematizar e (re)escrever-lhe o itinerário de vida na sua multidimensionalidade, conferindo um sentido histórico. (MAGALHÃES, 1996, p. 2)

O autor destaca que os estudos sobre instituições escolares devem contemplar três indissociáveis aspectos, a saber:

- a materialidade (o instituído): projeto arquitetônico, prédio, seus equipamentos, material didático e estrutura organizacional;

- a representação (a institucionalização): papel desempenhado pela instituição escolar, envolvendo tradição, modelos pedagógicos, currículo e funcionamento institucional;

- a apropriação (a instituição): as práticas pedagógicas propriamente ditas, os referenciais pedagógicos que norteiam as práticas e a identidade da escola e dos atores envolvidos nela (MAGALHÃES, 2004).

Nesta mesma direção, Maria Elizabeth Blank Miguel destaca a importância de se considerar o contexto econômico-cultural em que a instituição está inserida e as políticas educacionais que a orientam. Em sua percepção, a história das instituições só tem significado "quando compreendida à luz das políticas educacionais" (MIGUEL, 2007, p. 34). Alboni Marisa Dudeque Pianovski Vieira destaca que "as instituições escolares guardam importantes documentos que tratam das relações sociais e institucionais e como as políticas públicas educacionais foram implementadas naquele determinado contexto" (VIEIRA, 2013, p. 75).

Ao analisar os elementos ensejadores da criação de uma instituição, bem como sua história, seu público-alvo, suas propostas, sua arquitetura, entre outros aspectos, é possível identificar-lhe os pressupostos, pois as instituições escolares evidenciam a cosmovisão de uma época e defendem um projeto educativo calcado em valores vigentes na sociedade. 
O processo de historiar uma instituição educativa não terá muito sentido sem uma articulação entre o singular (instituição escolar) e o geral (contexto histórico), pois cada instituição educativa acompanha o desenrolar da sociedade conforme a produção da época. As instituições são compostas por elementos associados à formação da sociedade. O movimento no interior de uma instituição escolar reflete, geralmente, o movimento social em que ela está inserida, fundada na atividade econômica, porque cada período, concretamente, produz a relação sócio-educativa que lhe é própria (ALVES, 2007). A escola possui uma capacidade de, ao tempo em que recebe interferência do geral e do particular, exerce, também, certa influência sobre eles.

\section{Fontes e instituições escolares}

A pesquisa sobre instituições escolares é de caráter histórico-documental. É uma modalidade de investigação que contempla o levantamento e a análise das fontes. Vieira afirma que "a reconstrução da história das instituições escolares está intimamente relacionada à preservação e à organização dos seus arquivos, por meio dos quais se terá acesso às fontes que possibilitarão a pesquisa e a produção do conhecimento" (VIEIRA, 2013, p. 72). A reconstrução histórica das instituições escolares, como objeto de análise da história da educação, exige fontes, porque elas são a base, o ponto de apoio da análise histórica.

Ao se lançar nesta área de pesquisa, o historiador da educação se depara com a tarefa de levantar, catalogar e analisar documentos históricos que se constituem como fontes que oferecem importantes subsídios sobre a história. Isto significa que o historiador da educação tem a tarefa de constituir seu conjunto de fontes. Dependendo da época a ser analisada, a escassez de fontes é um problema comum. Na percepção de Carlos Bacellar, "[...] é preciso garimpar os documentos nas condições mais ou menos precárias em que se encontram" (BACELLAR, 2010, p. 45).

$\mathrm{Na}$ medida em que o historiador levanta problemas de pesquisa e recorre aos documentos na expectativa de extrair deles respostas às questões levantadas, atribui a 
alguns objetos a qualidade de fonte, pois neles há, potencialmente, respostas para as questões levantadas. O trabalho do pesquisador é buscar, mediante o trato dos documentos, uma aproximação do real que lhe possibilite encontrar respostas às suas questões. A grande quantidade de papéis encontrada nas bibliotecas e nos arquivos públicos e privados e os objetos guardados em museus não são em si mesmos fontes. Só recebem estatuto de fontes, segundo Saviani, na medida em que o historiador formular seu problema de pesquisa e decidir encontrar as respostas às questões levantadas naqueles objetos, que só se constituirão em fontes a partir do momento em que seja possível, com elas, produzir conhecimento histórico (SAVIANI, 2013a).

As fontes se constituem como elementos imprescindíveis para a sistematização do conhecimento histórico. Paulino José Orso define fontes como os "documentos, registros, marcas e vestígios deixados por indivíduos, por grupos, pelas sociedades e pela natureza que representam ou expressam uma determinada forma de ser da matéria, seja ela natural, humana ou social, em seu processo de contradição e transformação" (ORSO, 2013, p. 43).

Identificar, usar e interpretar as fontes é fator preponderante na identificação da qualidade da pesquisa histórica, pois os documentos contêm vestígios e são testemunhas que manifestam as ações do homem no tempo (SILVA, 2010). Elas são indispensáveis para a realização de qualquer pesquisa em história e em história da educação. Nesta mesma perspectiva, Saviani afirma:

As fontes estão na origem, constituem o ponto de partida, a base, o ponto de apoio da construção historiográfica que é a reconstrução, no plano do conhecimento, do objeto histórico estudado. Assim, as fontes históricas não são a fonte da história, ou seja, não é delas que brota e flui a história. Elas, enquanto registros, enquanto testemunhos dos atos históricos, são a fonte do nosso conhecimento histórico, isto é, é delas que brota, é nelas que se apoia o conhecimento que produzimos a respeito da história. (SAVIANI, 2013, p, 13)

As fontes registram fatos concernentes à história dos homens e das sociedades. São produzidas pelo homem em suas relações com os outros homens e com a natureza. Servem como testemunhos dos atos históricos dos homens; por isso, são a própria fonte do conhecimento histórico (SAVIANI, 2004). Segundo Lombardi, as fontes resultam da 
ação histórica do homem. Elas registram seu modo de vida nas relações com outros em determinada sociedade (LOMBARDI, 2004). Jacques Le Goff afirma que "o documento não é qualquer coisa que fica por conta do passado; é um produto da sociedade que o fabricou segundo as relações de forças que aí detinham o poder” (LE GOFF, 2003, p.545). As fontes são o ponto de partida de uma pesquisa histórica. André Paulo Castanha diz que "são expressão do passado e, como tais, estão carregadas de sentidos que evidenciam/revelam características da sociedade que os produziu" (CASTANHA, 2013, p. 83).

Tendo em vista que dizem respeito à vida do homem e que este, por sua vez, faz história por meio de sua ação sobre a natureza para transformá-la e, no processo, se transforma a si mesmo, é correto dizer que o acesso às fontes representa o contato com objetos que revelam uma forma de vida e de organização social. Deste modo, pesquisar, levantar, catalogar e preservar fontes representa preservar a história do homem em seu processo de transformação ao longo do tempo (ORSO, 2013).

Na pesquisa sobre instituições escolares, o processo de seleção e organização dos documentos para pesquisa é complexo e se apresenta como um elemento desafiador ao historiador da educação. Ele dependerá muito do que vai encontrar em bibliotecas, arquivos e acervos, além de outros meios que viabilizam documentos. O desafio de organizar as fontes para reconstruir a história das instituições escolares se depara, na percepção de Saviani, com dois problemas recorrentes: as condições precárias de armazenamento e manutenção dos documentos por parte das instituições educativas, e o trabalho de articulação dos diversos tipos de fontes, sem deixar de considerar o fenômeno analisado (SAVIANI, 2004). O processo de preservação de fontes das instituições escolares traz à tona a expressão de sujeitos e grupos sociais que representam um determinado contexto histórico, e isso contribui para a compreensão da história da educação de uma sociedade (SILVA, 2013).

Nas pesquisas sobre instituições escolares, devem-se observar os critérios de escolha das fontes, que dependerá dos objetivos da pesquisa e do recorte temporal, do período que se propõe a analisar. De acordo com Lombardi, “considerando que todos os tipos de fontes são válidos para o entendimento do mundo e da vida dos homens, tem-se 
que convir que o tipo de fonte a ser utilizado decorre, em grande medida, do objeto de investigação" (LOMBARDI, 2004, p. 157).

As fontes e os documentos são a expressão do passado e estão carregados de sentidos que evidenciam características da sociedade que as produziu; por isso, elas não devem ser usadas de modo absolutamente objetivo. É preciso considerar os elementos subjetivos que compõem os documentos em si, bem como o trabalho do pesquisador no processo de análise. A análise documental, na perspectiva proposta por Júlio Aróstegui, “não é tarefa fácil, porque não é apenas ler um documento para captar seu sentido superficial, mas sim, para captar coisas concretas; por isso, a leitura deve ser orientada por perguntas" (ARÓSTEGUI, 2006, p. 521).

Os documentos não devem utilizados como portadores da verdade, nem como elementos meramente ilustrativos. Eles não falam por si mesmos. As fontes não são propriamente a realidade. Não registram exatamente o que aconteceu na instituição escolar que será pesquisada. Aróstegui assevera que investigar a história não é de modo algum transcrever o que as fontes existentes dizem (ARÓSTEGUI, 2006).

Cabe destacar que fontes e documentos escolares são importantes elementos para a pesquisa sobre tais instituições. Devem ser analisados à luz do contexto geral, ou seja, dos interesses conflitantes da sociedade que os produziu. Assim, deve ser cuidado do historiador não avaliar o particular, o pontual, sem antes adquirir uma compreensão mais abrangente da realidade. Segundo Maria Elizabeth Blanck Miguel, "para compreender melhor o que as fontes comunicam, se faz necessário que elas mesmas sejam consideradas dentro de sua história e em um contexto mais amplo, pois a compreensão da história das instituições escolares guarda uma profunda inter-relação com a história do contexto no qual tais instituições se situam" (MIGUEL, 2007, p. 38).

O trabalho de seleção e de organização dos documentos que servirão como fontes é complexo e demanda tempo; por isso, é dever do pesquisador ao avaliar os documentos estar munido de um aporte teórico-metodológico que o habilite a retirar as informações sócio-históricas e histórico-educativas neles presentes (ANDRADE, 2011). A opção por algumas e a exclusão de outras está em consonância com o referencial 
definido. Na percepção de Júlio Aróstegui, "as fontes adequadas para um tema são aqueles conjuntos documentais capazes de responder a um número maior de perguntas, com um número menor de problemas de fiabilidade, de equivocidade ou os que melhor se adaptam aos fins da pesquisa" (ARÓSTEGUI, 2006, p. 511).

Há que se destacar a importância da análise das fontes numa pesquisa sobre instituições escolares, pois são as perguntas que o pesquisador faz aos documentos que Ihes conferem sentido, pois documento algum é neutro, e sempre carrega consigo a opinião da pessoa e/ou do órgão que o escreveu (BACELLAR, 2011). Edgar Salvadori De Decca afirma que se for considerado que os documentos não falam por si, então, a questão da interpretação das fontes e das teorias e metodologias que o pesquisador assume se torna essencial para o desenvolvimento do trabalho historiográfico (DE DECCA, 2006). Teorizar a fonte, de acordo com Clarice Nunes, é ultrapassar a barreira simbólica que ela constitui para a compreensão do pesquisador; é findar com a ilusão positivista segundo a qual a simples referência é suficiente para garantir a veracidade dos fatos (NUNES, 2005, p. 72-73).

$\mathrm{Na}$ pesquisa sobre uma instituição escolar, devem-se priorizar fontes como: documentos oficiais da implantação da escola; quadro de professores; trajetória de exalunos; entrevistas com sujeitos envolvidos no processo de criação da instituição; legislação da época; currículo; cadernos dos alunos; jornais da época; práticas disciplinares, fotografias, entre outros (BUFFA, 2007).

\section{Pesquisa em arquivos}

Os arquivos são elementos importantes, principalmente em processos de pesquisa histórica, pois disponibilizam as fontes que servem de base para sua realização. Os acervos se organizam em conjuntos produzidos ou recebidos por instituições públicas e privadas e contêm documentos de natureza diversa. Eles decorrem do exercício de atividades específicas, tanto de entidades como de pessoas (MEDEIROS, 2013). São 
fundamentais na preservação das fontes e também da memória, ou da própria história, pois servem de acesso ao passado.

Isto, que vale para o geral, se aplica à história da educação. No Brasil, todavia, a preocupação em relação à importância dos arquivos na pesquisa educacional é recente e pouco disseminada. Segundo Clarice Nunes e Marta Maria Chagas de Carvalho, "as instituições portadoras de acervos (arquivos, bibliotecas, centros e documentação) estão no centro mesmo da constituição e redefinição do campo da história da educação" (NUNES; CARVALHO, 2005, p. 35).

Pesquisar em arquivos é uma atividade dura e desafiadora; exige disciplina e paciência. Este é um desafio constante para os que se envolvem nesta tarefa. O trabalho do pesquisador consiste, muitas vezes, em buscar papéis desorganizados; cabe a ele descobrir onde se localizam e quais podem ser úteis. Nesta empreitada, é muitas vezes preciso superar obstáculos de ordem burocrática, de boa vontade dos atendentes, de localização e de falta de formação adequada da parte de quem deveria facilitar a vida do pesquisador (SILVA, 2013). Nunes e Carvalho afirmam que "o gesto típico e necessário de o historiador ir aos arquivos é acompanhado de dois tipos de dificuldades: a de ordem mais geral, que afeta a existência das instituições-memória da sociedade e a de ordem específica, que tem a ver com a lógica das instituições que os guardam" (NUNES; CARVALHO, 2005, p. 33). De modo geral, os arquivos brasileiros enfrentam problemas comuns aos dos serviços públicos: falta de pessoal, de instalações adequadas e de recursos. Os arquivos não recebem, geralmente, atenção prioritária dos órgãos governamentais; por isso, são meros depósitos e papéis velhos (BACELLAR, 2010).

Por ser comum se encontrarem em condições pouco favoráveis à atuação do pesquisador exige-se dele conhecimento de normas arquivísticas, pois as políticas de suporte aos arquivos públicos e privados no Brasil são estabelecidas em lei. A Constituição Federal de 1988 e a Lei $n^{\circ} 8.159$, de 8 de janeiro de 1991, estabelecem que é dever do poder público, em todos os níveis, a gestão, a guarda e a preservação de documentos e arquivos como elementos de apoio à administração e à cultura. Bacellar destaca que "o historiador que se aventura nos arquivos, de qualquer época, deveria ter 
preocupações em conhecer o funcionamento da máquina administrativa para o período que pretende pesquisar" (BACELLAR, 2011, p. 44).

\subsection{Arquivo escolar}

Em relação às instituições escolares, os acervos documentais são imprescindíveis para o acesso às fontes. Muitas delas podem ser encontradas na própria instituição. Os documentos que podem ser encontrados na escola, que tratam de seu cotidiano, apresentam informações fundamentais à vida da instituição. Contudo, as precárias condições de manutenção representam um obstáculo a mais no processo de sua análise e interpretação. Segundo Décio Gatti Júnior, as escolas dispõem de um grande número de fontes e informações fundamentais para a construção de interpretações sobre elas próprias e sobre a história da educação (GATTI JÚNIOR, 2002). João Carlos da Silva lista algumas das importantes fontes disponíveis nos arquivos escolares: os prontuários dos alunos e os livros de matrículas (pelos dados sobre filiação e nacionalidade dos alunos e profissão dos pais); o livro de ponto e o livro de frequência (pelos nomes de professores e funcionários admitidos); as atas de diretoria e os relatórios (por conterem dados importantes sobre o funcionamento institucional e suas mudanças) (SILVA, 2013).

Nas instituições escolares são encontrados documentos que informam sobre a constituição das relações sociais da escola e sobre como as políticas públicas educacionais que foram por ela implementadas. Por tais funções, devem ser preservados, organizados e disponibilizados ao público; ser acessíveis aos que optam pelo caminho da pesquisa histórica sobre as instituições escolares. A despeito das dificuldades de preservação, algumas práticas podem ser estimuladas entre alunos, professores e funcionários, como: seleção, catalogação e acondicionamento de documentos considerados de maior relevância histórica e sua disponibilização a pesquisadores (VIEIRA, 2013).

Em geral, nas escolas, consideram-se documentos oficiais: ofícios, diários oficiais, requerimentos, relatórios, decretos, estatísticas, históricos escolares de alunos, atos de 
colação de grau, transferências, atas de reuniões pedagógicas, entre outros, que, obrigatoriamente, devem ser preservados e disponibilizados para pesquisas. Além dos documentos escolares oficiais, os arquivos das instituições educativas guardam outros documentos não oficiais, também úteis na investigação histórica: diários de classe, cadernos escolares, trabalhos de alunos, memórias de alunos e de professores. Vale destacar que a reconstituição histórica de uma instituição escolar depende, em grande medida, da preservação e organização de seus arquivos, pois é por meio deles que se terá acesso às fontes.

Quando uma escola que se pretende pesquisar não disponibiliza as fontes e documentos para realização de sua própria análise histórica com facilidade, esses documentos devem ser procurados em outros lugares. Tais instituições, em sua maioria, não têm o hábito de preservar os documentos. Dermeval Saviani alerta, a respeito, sobre a necessidade de se construir uma política de preservação de fontes que estabeleça critérios que definam que documentos, produzidos no interior da escola, se devem preservar ou descartar, pois sua preservação é de suma importância para se compreender a história da educação, uma vez que a escola faz parte da sociedade (SAVIANI, 2004).

Este trabalho de levantamento, organização, catalogação e preservação e de documentos em arquivos escolares exige a participação integrada de arquivistas, historiadores e técnicos.

\subsection{Fontes e arquivos na região oeste do Paraná}

O oeste paranaense é uma região de colonização recente - década de 1940 - se comparada ao restante do estado do Paraná; porém, as fontes primárias para pesquisa na região são escassas (relativamente ao aspecto que vimos tratando) e estão num estado de conservação que deixa muito a desejar, dadas as condições precárias de manutenção.

Outro fator digno de nota é a escassez de arquivos regionais que possibilitem sua preservação de forma adequada para efeito de recuperação da memória histórica. A história da educação no oeste do Paraná esteve, desde o início, vinculada à atuação de 
uma empresa colonizadora da região, a Industrial Madeireira Colonizadora Rio Paraná S/A. Muitas escolas fundadas nas décadas de 1940/1950 receberam auxílio financeiro desta empresa, em forma de doações de terrenos e madeiras, pois construir escolas atendia aos interesses desse grupo, que via na educação escolar um instrumento de sucesso na divulgação de suas terras. A questão da infraestrutura para os futuros colonos era importante para o êxito do empreendimento imobiliário. Assim, a realização de pesquisas sobre instituições na região deve considerar a importância dos documentos exarados da Industrial Colonizadora Madeireira Rio Paraná S/A. Grande parte deles está disponível em instituições públicas, que colaboraram para a construção da história educacional da região. O processo de mapeamento e organização dos arquivos, segundo Clarice Nunes, implica o permanente diálogo entre pesquisador e fontes documentais, para favorecer a expansão do conhecimento das fontes de história da educação e forçar o crescimento da historiografia, já que os próprios documentos constituem potencial gerador de novas pesquisas (NUNES, 2005).

A maior parte das fontes documentais para pesquisa sobre instituições escolares nessa região estão disponíveis em instituições públicas e privadas. É possível elencar e descrever os principais arquivos que armazenam e organizam essas fontes.

a) CEPEDAL (Centro de Estudos, Pesquisa e Documentação da América Latina): trata-se de um órgão suplementar, vinculado cientificamente ao Centro de Ciências Humanas, Educação e Letras (CCHEL) e, administrativamente, ao Campus de Marechal Cândido Rondon, da Universidade Estadual do Oeste do Paraná (UNIOESTE). Foi criado no ano de 1989. Desde esta data, tem-se especializado na organização e guarda de testemunhos e registros em vários suportes documentais sobre o oeste do Paraná e nas áreas de fronteira com o Paraguai e a Argentina. O objetivo deste órgão é preservar acervos documentais sobre o oeste paranaense e as populações de fronteira vinculadas à região. A instituição disponibiliza mais de 500 suportes documentais, entre entrevistas em áudio K7, VHS, CDs e discos de vinil. Tem acervo com mais de mil fotografias, particularmente sobre a ocupação da região, no período entre 1950 e 1990. Dispõe de uma biblioteca integrada ao sistema Apolo de bibliotecas da UNIOESTE, composta por mais de 2 mil livros. Possui também um acervo de periódicos com mais 50 títulos e 
aproximadamente 3 mil volumes; também mantém a revista Espaço Plural, um periódico publicado semestralmente em versão impressa e eletrônica. O CEPEDAL é sediado na UNIOESTE, campus Marechal Cândido Rondon. O endereço é: Rua Pernambuco, 1.777, Caixa Postal 91 - CEP 85960-000 e o sítio eletrônico: <http://www.unioeste.br/projetos/cepedal/>. Telefone (45) 3284-7878. O acervo está disponível aos pesquisadores por meio dos contatos acima apresentados.

b) Escritório da Industrial Madeireira Colonizadora rio Paraná S/A: localizado na cidade de Toledo, o escritório da empresa responsável pela ocupação do oeste paranaense constitui importante acervo para pesquisa sobre história da educação regional e instituições escolares. Possui materiais referentes à movimentação financeira da empresa no período da colonização, como: mapas, imagens, contratos de compra e venda de terrenos, termos de doação de terrenos e madeiras à escolas e igrejas como incentivo à construção e dados sobre sua atuação como colonizadora. Tem sede na Rua Guarani, 1.460, Centro (Toledo/PR). Telefone: (45) 5277-1308. O acervo está disponível para realização de pesquisas com agendamento prévio, através dos contatos indicados.

c) Biblioteca da Universidade Estadual do Oeste do Paraná: os campi de Cascavel, de Toledo e de Marechal Cândido Rondon da UNIOESTE possuem um considerável número de trabalhos defendidos nos cursos de graduação e de pós-graduação em história e história da educação, que discutem a questão da colonização e da escolarização da região. Estes acervos estão disponíveis para serem consultados por pesquisadores que se decidem pela pesquisa de instituições escolares. Os campi de cada uma dessas cidades possuem bibliotecas com vasto material para pesquisas sobre instituições escolares. $\mathrm{O}$ Sistema de Bibliotecas da UNIOESTE disponibiliza acesso a todo seu acervo. A biblioteca do campus Cascavel está localizada no seguinte endereço: Rua Universitária, 1.619. Caixa Postal 701, Jardim Universitário. Cascavel, Paraná - CEP 85819-110. Telefone: (45) 32203178. Coordenadora da Biblioteca: Neusa Fagundes. Campus de Marechal Cândido Rondon: Rua Pernambuco, 1.777, Caixa Postal 91 CEP 85960-000. Telefone: (45) 32847817; coordenadora da biblioteca: Marcia Elisa Sbaraini Leitzke. Campus de Toledo: Rua da Faculdade, 645-Jardim Santa Maria, CEP. 85903-000 Toledo/PR. Telefone: (45) 33797118. Coordenadora da biblioteca: Loia Inez Mallmann. 
E mail: bibtoledo@unioeste.br. O sítio eletrônico para acesso às três bibliotecas acima elencadas é:<http://www.unioeste.br/biblioteca/>.

d) Biblioteca particular da família de Ondy Hélio Niederauer: trata-se de um exfuncionário Industrial Madeireira Colonizadora Rio Paraná S/A, que atuou à época da colonização da região. Ondy publicou a obra: Toledo no Paraná: a história de um latifúndio improdutivo, sua reforma agrária, sua colonização, seu progresso. Foi editado em 2004, pela editora regional: Tolegraf. Embora o autor disponibilize um importante número de fontes em sua obra, há muitas mais disponíveis no acervo particular da família, especialmente materiais sobre a vida e a atuação dos migrantes fundadores e seus descendentes.

e) Museu histórico Willy Barth: trata-se de uma instituição pública municipal, localizada em Toledo. É um espaço destinado à conservação de documentos diversos. Foi criado pela Lei Municipal nº 834, de 23 de agosto de 1976; seu acervo possui mais de 15 mil itens, divididos em:

- imagens, documentos impressos (livros; revistas; biografias), entre outros, e manuscritos;

- mapas; correspondências; jornais; relatórios de atuação da empresa colonizadora;

- documentos pessoais;

- peças/objetos de uso doméstico e comercial;

- história oral: depoimentos de pessoas diretamente envolvidas no processo de ocupação da região, gravados em áudio e vídeo, todos relativos à colonização e à escolarização do oeste paranaense.

O Museu Histórico Willy Barth constituiu-se como importante acervo de fontes documentais sobre a história da educação da região e sobre as instituições escolares. Situado na Avenida Tiradentes, no Centro Cultural "Oscar Silva”, no centro comercial de Toledo, o museu está aberto à visitação de segunda a sexta-feira, das 8 hoo às 11 h45 e das 13h30 às 17h30. Telefone: (45) 3277 3590, e-mail: museu@toledo.pr.gov.br. 
Sítio eletrônico: <http://www.toledo.pr.gov.br/portal/cultura/museu-historicowilly-barth>.

f) Projeto História Viva: projeto desenvolvido por professores e alunos da UNIOESTE, campus Marechal Cândido Rondon, o projeto teve início na década de 1980. Seu objetivo principal é resgatar o conhecimento histórico a partir dos relatos orais de colonizadores e fundadores dos municípios da região. O Projeto História Viva está sediado na UNIOESTE, campus Marechal Cândido Rondon. Endereço: Rua Pernambuco,

1.777, Caixa Postal 91 - CEP 85960-000 e o sítio eletrônico <http://www.unioeste.br/projetos/cepedal/>. Telefone (45) 3284-7878. O acervo está disponível aos pesquisadores por meio dos contatos acima apresentados.

\section{Conclusão}

A despeito da ampliação da discussão sobre a importância de se conservar as fontes para o conhecimento do patrimônio cultural e histórico, os pesquisadores na área de história da educação ainda encontram dificuldades, especialmente no que concerne ao acesso e à conservação dos documentos.

Na região oeste paranaense, a situação de conservação das fontes é muito precária e descuidada, principalmente em relação à documentação do início do século XX. A escassez de fontes sobre a história da educação é uma realidade na pesquisa sobre as instituições escolares da região; no entanto, é possível realizar pesquisas e a tarefa é de grande dimensão. Por se tratar de uma região de colonização recente, faz-se necessário documentar a história. Cabe destacar que o trabalho de levantamento e catalogação de fontes primárias e secundárias relativas à história da educação desta região tem sido realizado por algumas instituições públicas e grupos de pesquisa. O HISTEDOPR, GTCascavel, grupo de pesquisa vinculado ao HISTEDBR/Unicamp, em desenvolvimento desde 2003, tem-se dedicado à tarefa de levantar, organizar e catalogar fontes primárias e secundárias para a história da educação na região oeste do Paraná, mas ainda há muito que se fazer. 
O trabalho de reconstituição da história e da memória da educação e das instituições escolares na região oeste do Paraná tem representado um desafio aos pesquisadores na área de história da educação, pois essas fontes, em sua maioria, já se perderam ou estão se perdendo, devido à escassez de acervos documentais regionais. A documentação está dispersa, sem acondicionamento adequado; por isso está se deteriorando e se perdendo.

Portanto, há que se desenvolver uma cultura de preservação das fontes na região. Para tal, as instituições escolares podem contribuir por meio da preservação de documentação. Isto não significa guardar tudo, mas descartar o desnecessário e criar condições mínimas de sobrevivência do suporte físico (materialidade) e da informação do documento. Deve haver um trabalho integrado entre as secretarias das escolas, os arquivistas e os historiadores da educação visando à elaboração de planos de destinação aos documentos escolares. Tal exercício poderá auxiliar na definição do que se entenda por documento escolar, e o que deve ser preservado e o que deve ser descartado dos arquivos (VIDAL, 2007).

A qualidade das pesquisas sobre instituições escolares no oeste do paranaense depende de um rigoroso trabalho de preservação de fontes por parte das escolas da região. Isto se dará por meio do melhoramento da infraestrutura, da organização dos arquivos e do compromisso coletivo. 


\section{Referências}

ALVES, Gilberto Luiz. Em busca da historicidade das práticas escolares. In: NASCIMENTO, Maria Isabel Moura; SANDANO, Wilson; LOMBARDI, José Claudinei; SAVIANI, Dermeval. (Org.). Instituições Escolares no Brasil: conceito e reconstrução histórica. Campinas: Autores Associados, 2007. p. 255 -266.

ANDRADE, Rodrigo Pinto de. História e historiografia da Escola Luterana Concórdia de Marechal Candido Rondon (1955-1969). 2011. 266 f. Dissertação (Mestrado em Educação) Programa de Pós-Graduação em Educação, Universidade Estadual de Maringá, 2011.

ARNAUT DE TOLEDO, Cézar de Alencar; ANDRADE, Rodrigo Pinto de. História e historiografia da Escola Lutera Concórdia de Marechal Cândido Rondon (1955-1969). In: SILVA, João Carlos da, ORSO, José Paulino, CASTANHA, André Paulo, MAGALHÃES, Lívia Diana Rocha (Org.). História da Educação: arquivos, instituições escolares e memória histórica. Capinas: Alínea, 2013. p. 191-210.

ARAUJO, José Carlos Souza. As Instituições escolares na primeira república: ou os projetos educativos em busca de hegemonia. In: NASCIMENTO, Maria Isabel Moura; SANDANO, Wilson; LOMBARDI, José Claudinei; SAVIANI, Dermeval. (Org.). Instituições escolares no Brasil: conceito e reconstrução histórica. Campinas: Autores Associados, 2007. p. 95-122.

ARÓSTEGUI, Júlio. A pesquisa histórica: teoria e método. Bauru: EDUSC, 2006.

BACELLAR, Carlos. Uso e mau uso dos arquivos. In: PINSKY, Carla Bassanezi. (Org.). Fontes históricas. São Paulo: Contexto, 2011. p. 23-79.

BRASIL. Constituição Federal. [1988]. Disponível em: <http://www.planalto.gov.br/ccivil_03/constituicao/constitui\%C3\%A7ao.htm>. Acesso em: 10 nov. 2010.

BRASIL. Lei Federal n. 8.159. [1991]. Disponível em:

<http://www.planalto.gov.br/ccivil_03/leis/L8159.htm>. Acesso em: 11 nov. 2013.

BUFFA, Ester. Os estudos sobre instituições escolares: organização do espaço e propostas pedagógicas. In: NASCIMENTO, Maria Isabel Moura; SANDANO, Wilson; LOMBARDI, José Claudinei; SAVIANI, Dermeval. (Org.). Instituições escolares no Brasil: conceito e reconstrução histórica. Campinas: Autores Associados, 2007. p. 151-164.

CASTANHA, André Paulo. Retornas às fontes: desafios aos estudos histórico-educativos. In: SILVA, João Carlos da; ORSO, José Paulino; CASTANHA, André Paulo e MAGALHÃES, 
Lívia Diana Rocha. (Org.). História da educação: arquivos, instituições escolares e memória histórica. Campinas: Alínea, 2013. p. 79-94.

DE DECCA, Edgar Salvadori. Questões teórico-metodológicas da história. In. SAVIANI, Dermeval; LOMBARDI, José Claudinei; SANFELICE, José Luiz. (Org.). História e historiografia da educação: o debate teórico-metodológico atual. 3. ed. Campinas: Autores Associados: HISTEDBR, 2006. p. 17-24.

GATTI JÚNIOR, Décio. História das instituições educacionais: inovações paradigmáticas e temáticas. In: ARAÚJO, José Carlos Souza; GATTI JUNIOR, Décio. (Org.). Novos temas da educação: instituições escolares e educação na imprensa. Campinas: Autores Associados; Uberlândia: EDUFU, 2002. p. 3-24.

LE GOFF, Jacques. História e memória. Campinas: Editora da Unicamp, 2003.

LOMBARDI, José Claudinei. História e historiografia da educação: atentando para as fontes. In: LOMBARDI, José Claudinei; NASCIMENTO, Maria Izabel Moura. (Org.). Fontes, história e historiografia da educação. Campinas: Autores Associados, 2004. p. 141-160.

LOPES, Eliane Marta Teixeira, GALVÃO, Ana Maria de Oliveira. História da educação. Rio de Janeiro: DP\&A, 2001.

MAGALHÃES, Justino Pereira de. Contributo para a história das instituições educativa entre a memória e o arquivo. Braga: Universidade do Minho, 1996.

MAGALHÃES, Justino Pereira de. Tecendo nexos: história das instituições educativas. Bragança Paulista: EDUSF, 2004.

MEDEIROS, R. Arquivos escolares: breve introdução a seu conhecimento. In: Simpósio do Museu Pedagógico, 3, 2003. Bahia. Disponível em: <http://www.histedbr.fae.unicamp.br>. Acesso em: 25 jul. 2013.

MIGUEL, Maria Elisabeth Blanck. Os Arquivos e fontes como conhecimento da história das instituições escolares. In: NASCIMENTO, Maria Isabel Moura; SANDANO, Wilson; LOMBARDI, José Claudinei; SAVIANI, Dermeval. (Org.). Instituições escolares no brasil: conceito e reconstrução histórica. Campinas: Autores Associados, 2007. p. 31-38.

NOSELLA, Paolo; BUFFA, Ester. As Pesquisas sobre instituições escolares: o método dialético marxista de investigação. EccoS - Revista Científica, São Paulo, v. 7, n.2, p. 351368, jul./dez.2005. 
NOSELLA, Paolo; BUFFA, Ester. As pesquisas sobre instituições escolares: balanço crítico. COLÓQUIO SOBRE PESQUISA DE INSTITUIÇÕES ESCOLARES, 2006, Campinas. Anais... Campinas: UNICAMP; São Paulo: UNINOVE, 2006.

NOSELLA, Paolo; BUFFA, Ester. Instituições escolares :por que e como pesquisar. Campinas: Alínea, 2009.

NÓVOA, António. Por que a história da educação? Petrópolis: Vozes, 2004.

NUNES, Clarice, CAVALHO, Marta Maria Chagas de. Historiografia da educação e fontes. In: GONDRA, José Gonçalves. (Org.). Pesquisa em história da educação no Brasil. Rio de Janeiro, DP\&A, 2005.

NUNES, Clarice. Interrogando a avaliação dos trabalhos de história da educação: o inventário de uma prática. In: GONDRA, José Gonçalves. (Org.). Pesquisa em história da educação no Brasil. Rio de Janeiro, DP\&A, 2005.

ORSO, Paulino José. História, instituições, arquivos e fontes na pesquisa e na história da educação. In: SILVA, João Carlos da; ORSO, José Paulino; CASTANHA, André Paulo; MAGALHÃES, Lívia Diana Rocha. (Org.). História da educação: arquivos, instituições escolares e memória histórica. Campinas: Alínea, 2013. p. 34-48.

RAGAZZINI, Dário. Os estudos histórico-educativos e a história da educação. In: SANFELIE, José Luiz; SAVIANI, Dermeval; LOMBARDI, José Claudinei. História da educação: perspectivas para um intercâmbio internacional. Campinas: Autores Associados, 1999. p.19-35.

SANFELICE, José Luís. História das instituições escolares. In: NASCIMENTO, Maria Isabel Moura; SANDANO, Wilson; LOMBARDI, José Claudinei; SAVIANI, Dermeval. (Org.). Instituições escolares no Brasil: conceito e reconstrução histórica. Campinas: Autores Associados, 2007. p. 75-93.

SAVIANI, Dermeval. Instituições de memória e organização de acervos para a história das instituições escolares. In: SILVA, João Carlos da; ORSO, José Paulino; CASTANHA, André Paulo; MAGALHÃES, Lívia Diana Rocha. (Org.). História da educação: arquivos, instituições escolares e memória histórica. Campinas: Alínea, 2013a. p.13-31.

SAVIANI, Dermeval. Aberturas para a história da educação: do debate teóricometodológico no campo da história ao debate sobre a construção do sistema nacional de educação no Brasil. Campinas: Autores Associados, 2013b. 
SAVIANI, Dermeval. Breves Considerações sobre as fontes para a história da educação. In: LOMBARDI, José Claudinei; NASCIMENTO, Maria Isabel Moura. (Org.). Fontes, história e historiografia da educação. Campinas: Autores Associados, 2004. p. 3-12.

SILVA, João Carlos da et.al. História e memória educacional na região Oeste do Paraná. In: SILVA, João Carlos da; ORSO, José Paulino; CASTANHA, André Paulo; MAGALHÃES, Lívia Diana Rocha. (Org.). História da educação: arquivos, instituições escolares e memória histórica. Campinas: Alínea, 2013. p. 173-189.

SILVA, João Carlos da. et.al. Grupos de pesquisa e a história da educação brasileira: o itinerário do HISTEDOPR. In: CASTANHA, André Paulo; ORSO, José Paulino; SILVA, João Carlos da. (Org.). História da educação: pesquisa, levantamento de fontes e instituições escolares. Cascavel: EDUNIOESTE, 2010. p. 21-39.

VIEIRA, Alboni Marisa Dudeque Pianovski. Instituições escolares: memória, fontes, arquivos e novas tecnologias. In: SILVA, João Carlos da; ORSO, José Paulino; CASTANHA, André Paulo; MAGALHÃES, Lívia Diana Rocha. (Org.). História da educação: arquivos, instituições escolares e memória histórica. Campinas: Alínea, 2013. p. 65 -78.

VIDAL, Diana Gonçalves. Por uma ampliação da noção de documentos escolar. In: NASCIMENTO, Maria Isabel Moura; SANDANO, Wilson; LOMBARDI, José Claudinei; SAVIANI, Dermeval. (Org.). Instituições escolares no Brasil: conceito e reconstrução histórica. Campinas: Autores Associados, 2007. p. 59-71.

WARDE, Mirian Jorge. Questões teóricas e de método: a história da educação nos marcos de uma história das disciplinas. In. SAVIANI, Dermeval; LOMBARDI, José Claudinei; SANFELICE, José Luiz. (Org.). História e historiografia da educação: o debate teóricometodológico atual. 3. ed. Campinas: Autores Associados; HISTEDBR, 2006.

Recebido em: 29/11/2013 Aprovado em: 12/02/2014

Universidade do Estado de Santa Catarina - UDESC Programa de Pós-Graduação em Educação - PPGE Revista Linhas Volume 15 - Número 28 - Ano 2014 revistalinhas@gmail.com 